\title{
Silencing of uPAR via RNA interference inhibits invasion and migration of oral tongue squamous cell carcinoma
}

\author{
XUEXIANG GAO $^{1}$, QI GUO $^{1}$, SHUO WANG $^{1}, \mathrm{CEN} \mathrm{GAO}^{1}$, \\ JIAN CHEN $^{2}$, LI ZHANG ${ }^{1}$, YUAN ZHAO ${ }^{1}$ and JING WANG ${ }^{1}$ \\ ${ }^{1}$ School of Stomatology, Lanzhou University; ${ }^{2}$ Department of Pediatric Surgery, \\ The First Hospital of Lanzhou University, Lanzhou, Gansu 730000, P.R. China
}

Received January 30, 2016; Accepted May 1, 2018

DOI: $10.3892 / \mathrm{ol} .2018 .9094$

\begin{abstract}
Overexpression of urokinase-type plasminogen activator receptor (UPAR) has been implicated in promoting tumor invasion in various cancer types, including oral tongue squamous cell carcinoma (OTSCC); therefore, the effect of suppressing uPAR expression on the invasive and metastatic potential of OTSCC was investigated. A total of 65 paraffin-embedded tissues were obtained from patients with OTSCC. Immunohistochemistry was used to determine the expression level of uPAR. The Ts cells transfected with short hairpin RNA targeting uPAR were constructed and validated. The cells were used in a number of in vitro analyses, including migration, invasion and western blot analysis assays. Furthermore, a mouse lung metastatic model was used to detect the metastatic ability of OTSCC cells in the lungs. OTSCC cell metastasis and relapse were determined to be associated with uPAR immunopositivity. Inhibition of UPAR expression in Ts cells demonstrated a $40 \%$ decrease in migration and a $60 \%$ decrease in invasion in vitro, with an associated downregulation of matrix metalloprotease (MMP)-2, MMP-9 and phosphorylated extracellular signal-regulated kinase. In vivo analysis indicated a $90 \%$ decrease in the number of mice bearing macroscopic lung metastases. In conclusion, the present study demonstrated that the targeting of uPAR-inhibited cellular proliferation and invasion would provide a potential treatment for OTSCC in the future.
\end{abstract}

Correspondence to: Ms. Jing Wang or Ms. Yuan Zhao, School of Stomatology, Lanzhou University, 199 Donggang Road, Lanzhou, Gansu 730000, P.R. China

E-mail: lzukqwj@126.com

E-mail: zhaoy@1zu.edu.cn

Key words: urokinase-type plasminogen activator receptor, oral tongue squamous cell carcinoma, RNA interference, invasion, migration

\section{Introduction}

Oral tongue squamous cell carcinoma (OTSCC) is one of the most common types of malignancy in the head and neck region and specifically in the oral cavity, with a global incidence estimated at 275,000 novel cases/year in 2002 (1). Although treatments have progressed over the past two decades, 5 -year survival rates have remained at a low level of $50 \%$ (2). The high death rate is caused by frequent invasion and metastasis, and the identification of the associated target molecules are necessary prerequisites for the early detection of OTSCC and the identification of treatment strategies (3).

Urokinase-type plasminogen activator receptor (UPAR) is involved in tissue reorganization events, including mammary gland involution and wound healing. UPAR focuses uPA proteolytic activity on the cell membrane, mediates cell adhesion to vitronectin and activates cell signaling pathways by associating with cell surface molecules (4). Previous studies have demonstrated that uPAR has an increased expression in numerous malignant tumor types, including oral squamous cell, breast and pancreatic carcinomas (5-7), and it has been indicated to regulate a number of events, including angiogenesis, immune suppression and cell migration (8). Therefore, it has been considered that activation of UPAR serves a notable role in cancer cell invasion and is correlated with a poor long-term prognosis (9). However, the mechanism underlying the role of UPAR in OTSCC invasion and migration is not completely understood.

Ts cells, established and characterized at the Department of Oral Biology, College of Stomatology, Fourth Military Medical University Laboratory, exhibited a higher metastatic potential than the parental Tca-8113 cells in vitro and in vivo (10). In our previous study, the Ts cells transfected with short hairpin RNA (shRNA) targeting uPAR were successfully constructed and identified (11). On this basis, the aim of the present study was to investigate the effects of uPAR inhibition on tumor cell invasion and metastasis in the OTSCC Ts cell line via RNA interference. The results of the present study indicated that blocking uPAR in the OTSCC cells decreased the progression and invasion in vitro and decreased the number of lung metastases in orthotopic models; therefore, combination therapies targeting UPAR may represent a novel therapeutic approach that synergistically decreases the invasion and metastasis of OTSCC in the future. 


\section{Materials and methods}

Cell culture and transfection. The Ts cell line was obtained from the Department of Oral Biology, College of Stomatology, Fourth Military Medical University. This cell line was established from cells obtained from the brain metastases of nude mice that had been injected with TCA8113 cells. Plasmid pWH1 was designed by Dr. Wu Yuan-Ming (Department of Pathology and Pathophysiology of the Fourth Military Medical University) (12). Lipofectamine ${ }^{\circledR} 2000$ Transfection reagent (catalog no. 11668019) were purchased from Invitrogen (Thermo Fisher Scientific, Inc., Waltham, MA, USA). Bgl II, EcoL I and Hind III were purchased from Takara Bio Inc. (Otsu, Japan). The Ts cells transfected with pWH1-upar $(0.8 \mu \mathrm{g} / 50 \mu \mathrm{l}$; obtained from Dr Wu Yuan-Ming, Department of Pathology and Pathophysiology of the Fourth Military Medical University) expression vector exhibited a lower mRNA and protein expression of Upar for $48 \mathrm{~h}$. In control group (shRNA-C), transfection was performed by transfecting Ts cells with pWH1 $(0.8 \mu \mathrm{g} / 50 \mu \mathrm{l}$; obtained from Dr. Wu Yuan-Ming, Department of Pathology and Pathophysiology of the Fourth Military Medical University) for 48 h. Control cells were incubated with Dulbecco's modified Eagle's medium (DMEM; Gibco; Thermo Fisher Scientific, Inc.; catalog no: 12491-015) alone without shRNA. Cells were grown in DMEM supplemented with 10\% fetal calf serum (Gibco; Thermo Fisher Scientific, Inc.; catalog no: 10099141) in a humidified atmosphere containing $5 \% \mathrm{CO}_{2}$ at $37^{\circ} \mathrm{C}$ for $24 \mathrm{~h}$.

Immunohistochemistry. Immunohistochemical studies were conducted on sections of paraffin-embedded tissues of clinical OTSCC samples. All the patients $(\mathrm{n}=65 ; 42$ male, 23 female; age range, $40-85$ years; mean age, 64 years) were examined and treated at The First Hospital of Lanzhou University Lanzhou, China or Lanzhou University Second Hospital, Lanzhou, China between January 2010 to January 2013. Eligibility criteria included that patients had not received postoperative adjuvant therapy, including chemotherapy or radiotherapy, or any other treatment prior to surgery. Tissues were fixed in $4 \%$ paraformaldehyde at $4^{\circ} \mathrm{C}$ for $24 \mathrm{~h}$ and were embedded in paraffin. For immunohistochemistry, surgically-resected OTSCC samples, including adjacent tissues, were cut to a thickness of $4 \mu \mathrm{m}$. The sections were sequentially dewaxed in xylene, rehydrated with a descending alcohol series $(100,95,90,80,70 \%)$ and distilled water and then subjected to antigen retrieval for $30 \mathrm{~min}$ at $95^{\circ} \mathrm{C}$. Normal goat serum (catalog no. 5425; Cell Signaling Technology, Inc., Danvers, MA, USA) in PBS was used as blocking buffer for $1 \mathrm{~h}$ at $37^{\circ} \mathrm{C}$. The slides were subsequently incubated overnight at $4^{\circ} \mathrm{C}$ with a primary rabbit polyclonal antibody specific against uPAR (1:100; catalog no. 12713; Cell Signaling Technology, Inc., Danvers, MA, USA). Slides were then treated with an biotin-conjugated goat anti-rabbit secondary antibody (catalog no. TA130016; OriGene Technologies, Inc., Beijing, China) diluted in $0.01 \mathrm{M}$ PBS (1:100) at room temperature for $1 \mathrm{~h}$ and developed using avidin-conjugated horseradish peroxidase with 3,3'-diaminobenzidine as a substrate (OriGene Technologies, Inc.), followed by hematoxylin counterstaining for $10 \mathrm{~min}$ at room temperature. The assessment of the UPAR expression level was classified according to semi-quantitative immunohistochemistry (13). uPAR immunoreactivity was scored separately in cancerous or adjacent non-cancerous sections, as described previously (14). The slides were reviewed with a light microscope (x100, x200 and $\times 400)$ by two investigators blind to the clinical diagnosis of OTSCC.

Wound-healing assay. To determine the effects of UPAR shRNA transfection on the motility of the Ts cell line, cells were plated at $1 \times 10^{5} /$ well in a 6-well plate in DMEM supplemented with $10 \%$ fetal bovine serum (FBS) (Gibco; Thermo Fisher Scientific, Inc.). Once the cells reached $90 \%$ confluency, sterile pipette tips were used to scratch a wound $\sim 600-\mu \mathrm{m}$ wide uniformly. Following this, the cells were washed with PBS, and DMEM was added with $10 \mathrm{~g} / \mathrm{l}$ bovine serum albumin. After $24 \mathrm{~h}$ of incubation at $37^{\circ} \mathrm{C}$, the medium was replaced with fresh DMEM supplemented with 10\% FBS. The scratched area was imaged with a $\times 100$ magnification light microscope at 0 and $24 \mathrm{~h}$. Cell migration was analyzed using ImageJ (version 1.48) software (National Institutes of Health, Bethesda, MD, USA) by counting the number of cells in the scratched areas. Each experiment was conducted in triplicate.

Tumor cell invasion assay. The invasion assay was performed with Matrigel-coated Transwell inserts (8- $\mu \mathrm{m}$ pore size; EMD Millipore, Billerica, MA, USA). Isolated cells at a concentration of $1 \times 10^{5} \mathrm{cells} /$ well resuspended in DMEM were placed into the upper chamber. DMEM with 20\% FBS was placed into the lower chamber. Cells were allowed to migrate through the Matrigel for $48 \mathrm{~h}$. After $48 \mathrm{~h}$, non-invading cells were removed from the upper chamber using a cotton swab. Invading cells that adhered to the outer surface of the Transwell insert or that had invaded through the Matrigel were fixed in methanol and stained with crystal violet for $0.5 \mathrm{~h}$ at $37^{\circ} \mathrm{C}$. The invasiveness was determined by counting the penetrated cells under a light microscope at x200 magnification in 10 randomly selected fields in each filter. Each experiment was performed in triplicate.

Western blot analysis. Western blot analysis was performed using standard techniques (15). Briefly, the three groups of harvested cells were washed with PBS and lysed with RIPA buffer (catalog no. 9806; Cell Signal Technology, Inc.). The protein concentration was determined using a bicinchoninic acid protein assay kit (Thermo Fisher Scientific, Inc.). Protein samples $(20 \mu \mathrm{g})$ were separated in $10 \%$ SDS-PAGE by electrophoresis and subsequently transferred onto a polyvinylidene fluoride (PVDF) membranes by electroblotting. Following electrophoresis and transfer to PVDF membranes, then blocked with 5\% non-fat dried milk for $1 \mathrm{~h}$ at room temperature and detection of specific proteins was conducted using antibodies) against matrix metalloprotease (MMP)-9 (catalog no. 13667; 1:1,000), MMP-2 (catalog no. 87809; 1:1,000), phosphorylated-extracellular signal-regulated kinase (p-ERK) (catalog no. 4370; 1:1,000), ERK (catalog no. 4695; 1:1,000), p-protein kinase B (p-Akt; catalog no. 9271; 1:2,000), Akt (catalog no. 4691; 1:1,000) and GAPDH (catalog no. 5174, 1:1,000) (Cell Signaling Technology, Inc.) overnight at $4^{\circ} \mathrm{C}$. Following this, the immunoreactive bands were incubated with horseradish peroxidase-conjugated immunoglobulin $\mathrm{G}$ anti-rabbit secondary antibody (catalog no. 7074; dilution, 1:10,000; Cell Signaling Technology, Inc.) 
at room temperature for $2 \mathrm{~h}$. Subsequently, the signals were detected using enhanced chemiluminescence reagents X-ray films. Images were analyzed by ImageJ (version 1.48; National Institutes of Health, Bethesda, MD, USA).

In vivo metastasis assay. A total of 18 female athymic nude mice (4-5 weeks old; weight, 15-20 g) were purchased from Shanghai SLAC Laboratory Animal Co., Ltd. (Shanghai, China) and were fed with food and water ad libitum in a controlled atmosphere (temperature, $22 \pm 2^{\circ} \mathrm{C}$; humidity, $55 \pm 2 \%$ ) on a $12 / 12 \mathrm{~h}$ light/dark cycle. The three groups of $1 \times 10^{8}$ cells in $200 \mu \mathrm{l}$ culture medium (DMEM) were injected into the tail vein of the nude mice $(n=6)$. In accordance with the principles of animal ethics and without affecting the experimental results, we chose to sacrifice experimental animals by cervical dislocation and their lungs were collected to determine any metastases at 6 weeks after inoculation. Incidence of metastasis was determined by counting the number of macroscopic lesions on the surface of the lungs.

Statistical analysis. Data are presented as the mean \pm standard deviation of triplicate specimens per condition. The expression of UPAR in OTSCC tumor specimens and adjacent non-cancerous specimens was analyzed by the $\chi^{2}$ test. Differences between groups were analyzed by one-way analysis of variance. Least Significant Difference and Student-Newman-Keuls were used as the post hoc test using SPSS 13.0 software (SPSS, Inc., Chicago, IL, USA). P<0.05 was considered to indicate a statistically significant difference.

\section{Results}

Expression of $u P A R$ in Ts cells. To investigate the protein expression level of UPAR in OTSCC tumors and the association between tumor progression and metastasis, immunohistochemical analysis for UPAR on formalin-fixed OTSCC clinical tissue samples was conducted. Primary tissues exhibited cytoplasmic staining for uPAR (Fig. 1). A total of 46 tumor samples (70.8\%) were UPAR positive, whilst adjacent tissue samples rarely exhibited immunopositivity for $\operatorname{uPAR}(\mathrm{P}<0.001$; Table I). Further analysis of patient data revealed that tumor metastasis and relapse were the clinicopathological factors associated with uPAR positivity $(\mathrm{P}<0.05)$. Other parameters, including age $(\mathrm{P}=0.68)$, sex $(\mathrm{P}=0.653)$, pathological stage $(\mathrm{P}=0.839)$ and clinical stage $(\mathrm{P}=0.388)$, did not differ significantly between uPAR-positive and -negative groups (Table II).

Silencing of $u P A R$ affects the migratory potential of Ts cells in vitro. Following silencing uPAR in the Ts cell line, the differences in migratory capacities were measured using a wound-healing assay, in which the cells were scratched and then migrated into the wound area. The control group and the shRNA-C group demonstrated an $\sim 90.0 \%$ wound closure by $24 \mathrm{~h}$ after the initial wounding, the uPAR shRNA group demonstrated delayed migration with $\sim 58.7 \%$ wound closure in the same time period, indicating a significantly delayed migratory potential ( $\mathrm{P}<0.05$; Fig. 2$)$.

Silencing of $u P A R$ inhibited the invasion of Ts cells. To assess the differences in invasive potentials between the UPAR
Table I. Expression of uPAR in oral tongue squamous cell carcinoma and adjacent tissues.

\begin{tabular}{lcccc}
\hline & & \multicolumn{2}{c}{ uPAR expression } & \\
\cline { 3 - 4 } Tissue type & $\mathrm{n}$ & Positive & Negative & P-value \\
\hline Cancer tissue & 65 & 46 & 19 & $<0.001$ \\
Adjacent tissue & 28 & 6 & 22 & \\
\hline
\end{tabular}

Analyzed by $\chi^{2}$ test. uPAR, urokinase-type plasminogen activator receptor.

Table II. Association between uPAR expression and clinicopathological variables in 65 patients with oral tongue squamous cell carcinoma.

\begin{tabular}{|c|c|c|c|c|}
\hline \multirow{2}{*}{$\begin{array}{l}\text { Clinicopathological } \\
\text { factor }\end{array}$} & \multicolumn{2}{|c|}{ uPAR expression } & \multirow[b]{2}{*}{$\chi^{2}$} & \multirow[b]{2}{*}{ P-value } \\
\hline & Positive & Negative & & \\
\hline Sex & & & 0.17 & 0.68 \\
\hline Male & 29 & 13 & & \\
\hline Female & 17 & 6 & & \\
\hline Age, years & & & 0.202 & 0.653 \\
\hline$>60$ & 27 & 10 & & \\
\hline$\leq 60$ & 19 & 9 & & \\
\hline Pathological stage & & & 0.351 & 0.839 \\
\hline $\mathrm{I}$ & 13 & 6 & & \\
\hline II & 22 & 7 & & \\
\hline III & 12 & 5 & & \\
\hline Clinical stage & & & 3.023 & 0.388 \\
\hline I & 5 & 3 & & \\
\hline II & 11 & 8 & & \\
\hline III & 22 & 6 & & \\
\hline IV & 8 & 2 & & \\
\hline Invasion/metastasis & & & 9.718 & 0.002 \\
\hline Yes & 24 & 2 & & \\
\hline No & 22 & 17 & & \\
\hline Relapse & & & 8.153 & 0.004 \\
\hline Yes & 25 & 3 & & \\
\hline No & 21 & 16 & & \\
\hline
\end{tabular}

uPAR, urokinase-type plasminogen activator receptor.

shRNA group and the parental Ts cells after $48 \mathrm{~h}$, Matrigel invasion assays were performed. Colorimetric analysis of the crystal violet-stained cells indicated a $\sim 60.0 \%$ decrease in the number of cells in the uPAR siRNA group, compared with the control group and the shRNA-C group, demonstrating a significantly lower invasive potential following silencing of uPAR in Ts cells $(\mathrm{P}<0.05$; Fig. 3$)$.

Silencing of UPAR decreases MMP-2, MMP-9 and p-ERK protein expression levels. Subsequently, the effect of uPAR on 


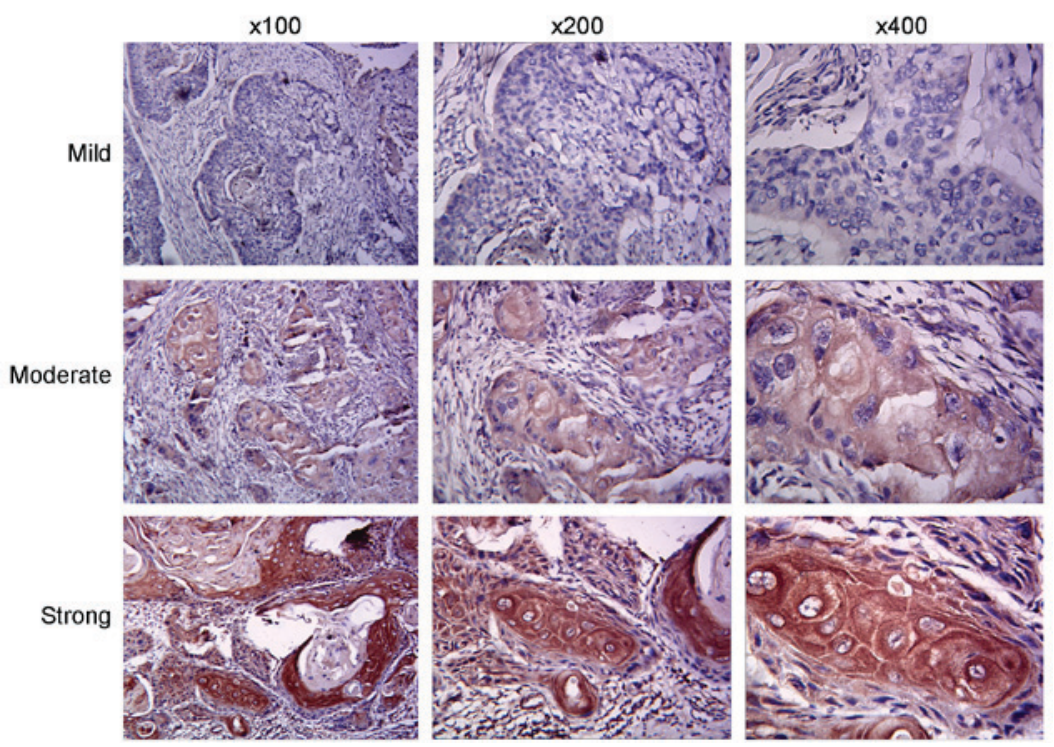

Figure 1. Immunohistochemical analysis of urokinase-type plasminogen activator receptor in oral tongue squamous cell carcinoma tissues.

A
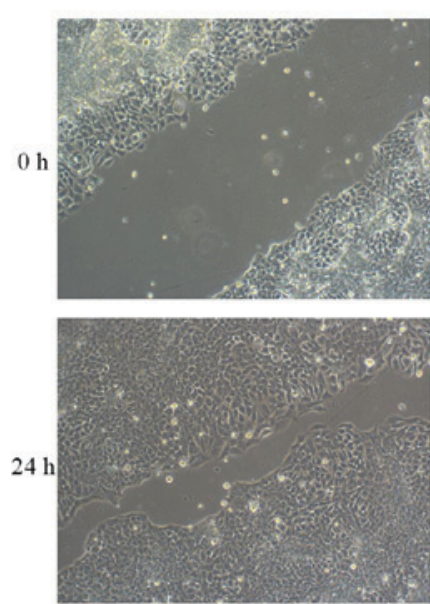

ShRNA-C
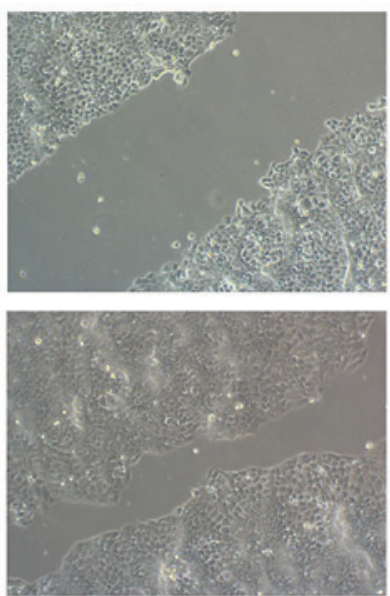

ShRNA-UPAR
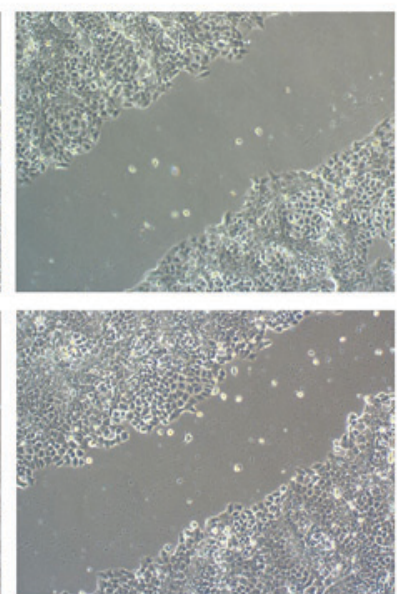

B

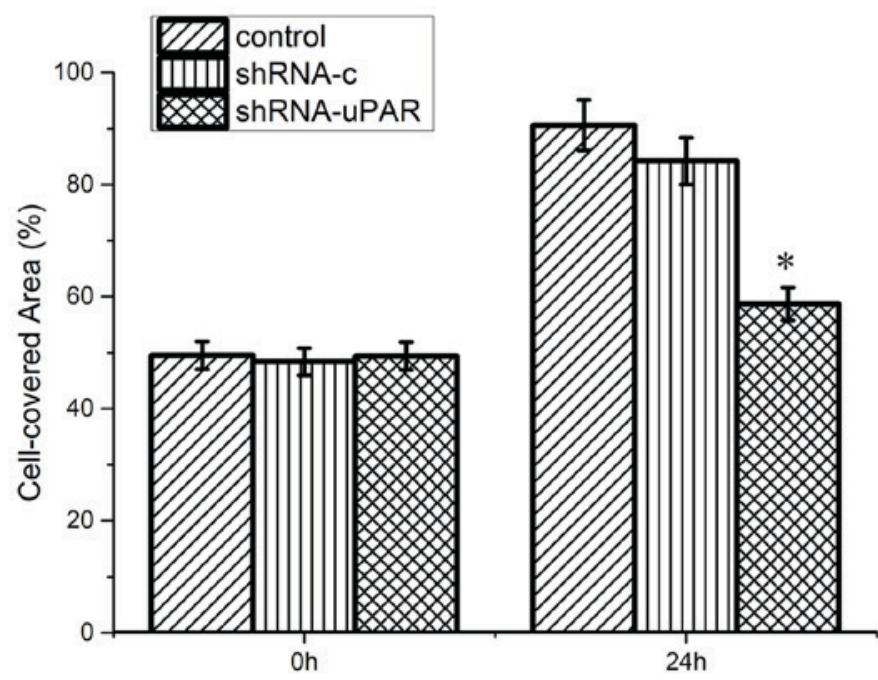

Figure 2. Silencing of uPAR decreases the migration of Ts cells after $24 \mathrm{~h}$. (A) The images of cell migration under an inverted microscope (magnification, x100). (B) The migratory coverage of the three groups of cells. ("P<0.05, compared with the shRNA-C and control groups after $24 \mathrm{~h}$ ). uPAR, urokinase-type plasminogen activator receptor; shRNA, short hairpin RNA. 
A

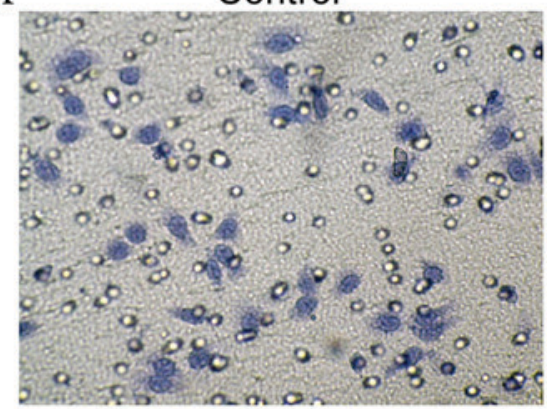

shRNA-C

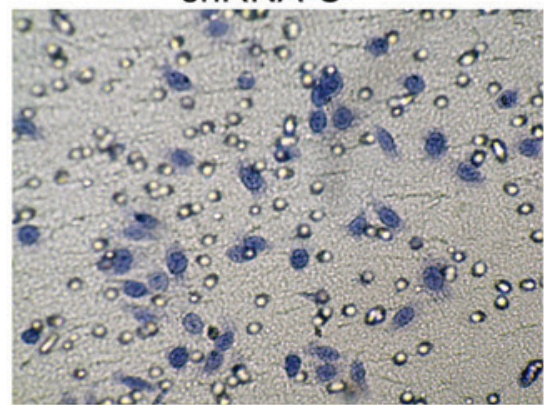

ShRNA-UPAR

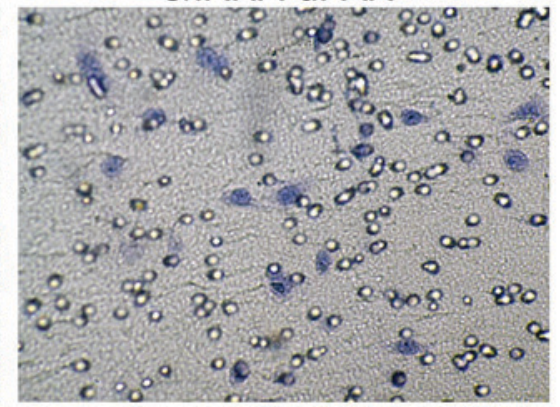

B

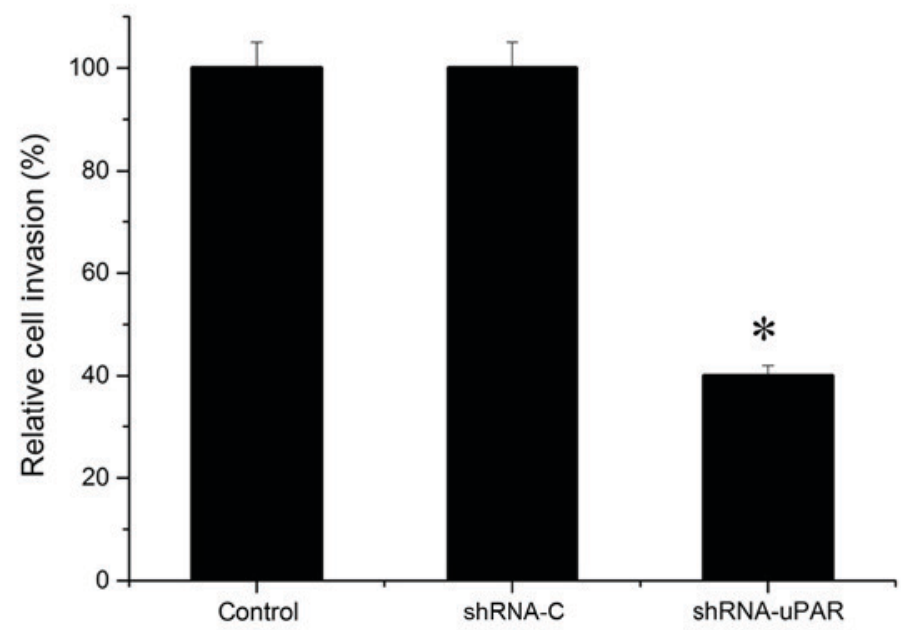

Figure 3. Silencing of uPAR inhibits Ts cells invasion. (A) A total of $1 \times 10^{5}$ Ts cells were seeded into Matrigel-coated Transwell inserts. Representative images of the cells that invaded through the Matrigel (x200 magnification). (B) The invading cells were counted in 10 randomly selected fields in each filter under an inverted microscope (x100 magnification). ( $\mathrm{P}<0.05$, compared with the control and shRNA-C groups). uPAR, urokinase-type plasminogen activator receptor; shRNA, short hairpin RNA.

the expression of invasion-associated molecules in Ts cells was examined using western blot analysis. Expression of matrix metalloproteinases is important in the migration and invasion of cancer cells through the basement membrane (16). It was observed that MMP-2 and MMP-9 protein expression levels were significantly decreased in the uPAR shRNA group, compared with the shRNA-C and control groups $(\mathrm{P}<0.05)$. Furthermore, the effects on the MEK/ERK and Akt signaling pathways were examined. The results, depicted in Fig. 4, indicated no significant change in Akt phosphorylation, but there was a $37.0 \%$ decrease in ERK phosphorylation $(\mathrm{P}<0.05)$, indicating a possible role of UPAR in the MEK/ERK signaling pathway involving mediation of the invasion and migration effects.

Silencing of UPAR suppresses the metastatic potential of Ts cells in vivo. To analyze the metastatic effect of uPAR in vivo, Ts cells were injected into the tail vein of nude mice and the presence of metastatic nodes in the lungs was evaluated after 6 weeks. Results depicted in Fig. 5 indicated a significant decrease in the number of metastatic nodes in the mice in the uPAR-shRNA group ( $\mathrm{P}<0.05$; Fig. 5).

\section{Discussion}

UPAR overexpression is associated with an increased propensity for cancer progression and metastasis, and thus it has emerged as a promising novel target for the treatment of cancer (17). Previous studies indicated that intact UPAR and its cleaved forms are associated with the process of tumor initiation (18) and metastasis (19). Results of the study by Margheri et al (20) indicated that silencing of UPAR altered the metastatic characteristics of advanced cancer; however, to the best of our knowledge, the mechanism underlying the role of UPAR in OTSCC invasion and migration has not been previously studied. uPAR activates cell-signaling pathways directed by proximal transmembrane co-receptors, including the epidermal growth factor receptor (21), and subsequently functions as a broad-spectrum protease that has the ability to degrade several extracellular matrix proteins (22) and activate latent growth factors and MMPs (23). Therefore, the critical role of UPAR along with the molecules involved in signaling cascades are potential therapeutic targets for cancer treatment.

In the present study, it was determined that UPAR may be associated with the progression of OTSCC. From the 65 samples, statistical analysis also revealed that uPAR expression was positively associated with tumor metastasis and relapse $(\mathrm{P}=0.002$ and $\mathrm{P}=0.004$, respectively) and were not significantly associated with sex $(\mathrm{P}=0.68)$, age $(\mathrm{P}=0.653)$, pathological stage $(\mathrm{P}=0.839)$ and clinical stage $(\mathrm{P}=0.388)$, indicating that uPAR may serve as a clinical factor for predicting a poor outcome. It was previously reported that the positive uPAR expression observed in breast cancer was correlated with tumor differentiation, clinical stage and lymphatic 
ShRNA

A
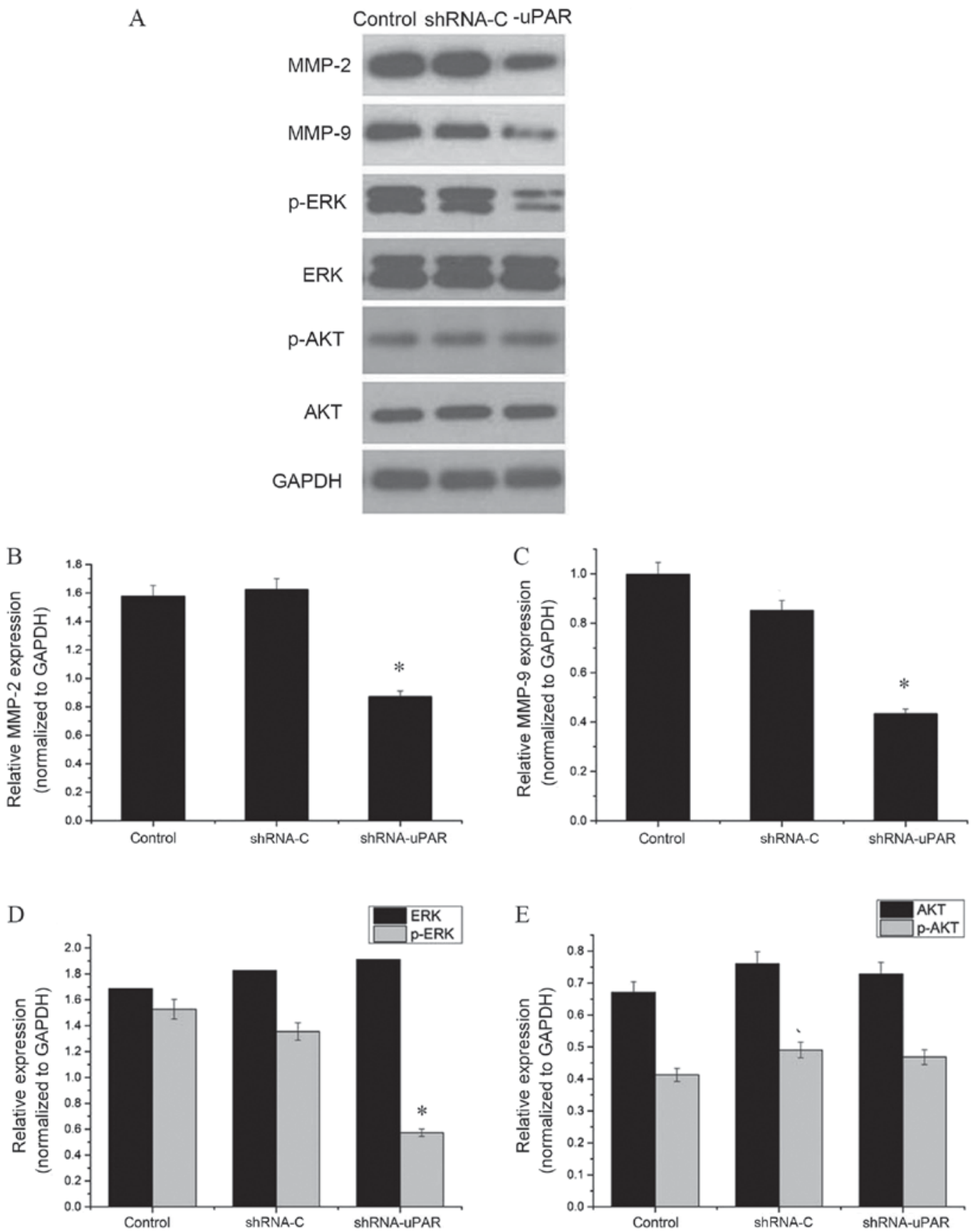

Figure 4. Western blot analysis of invasion-associated proteins. (A) The bands of western blot analysis. GADPH was used as an internal control. (B) MMP-2 protein expression levels were significantly decreased in the shRNA-uPAR group, compared with the shRNA-C and control groups ("P<0.05). (C) MMP-9 protein expression levels were significantly decreased in the shRNA-uPAR group, compared with the shRNA-C and control groups ("P<0.05). (D) ERK and p-ERK protein expression levels in the shRNA-uPAR, shRNA-C and the control groups. P-ERK protein expression levels were significantly decreased in the shRNA-uPAR group ("P<0.05, compared with the control and shRNA-C groups). (E) AKT and p-AKT protein expression levels in the shRNA-uPAR, shRNA-C and the control groups. Silencing of uPAR had no effect on the AKT protein expression levels (compared with the control and shRNA-C groups). MMP, matrix metalloprotease; p-ERK, phospho-extracellular signal-regulated kinase; p-Akt, phospho-Akt; uPAR, urokinase-type plasminogen activator receptor; shRNA, short hairpin RNA.

metastasis, which is consistent with the results of the present study (24).

Invasion and metastasis are not random, but are controlled by concerted action of multiple genes, which is a complex process and an important cause of cancer-associated mortality (25). The present study effectively demonstrated that silencing of uPAR inhibited the migratory and invasive potential of Ts cells, indicating that UPAR may contribute toward
OTSCC metastasis, which is in accordance with the results of previous studies that demonstrate that silencing of UPAR upregulates the progression and invasiveness (26) of OTSCC. These data are in accordance with the hypothesis that uPAR may serve a notable role in OTSCC progression.

The MEK/ERK (27) and phosphoinositide 3-kinase/Akt (28) signaling pathways have been thoroughly characterized previously. Previous studies have demonstrated that the ERK 
A
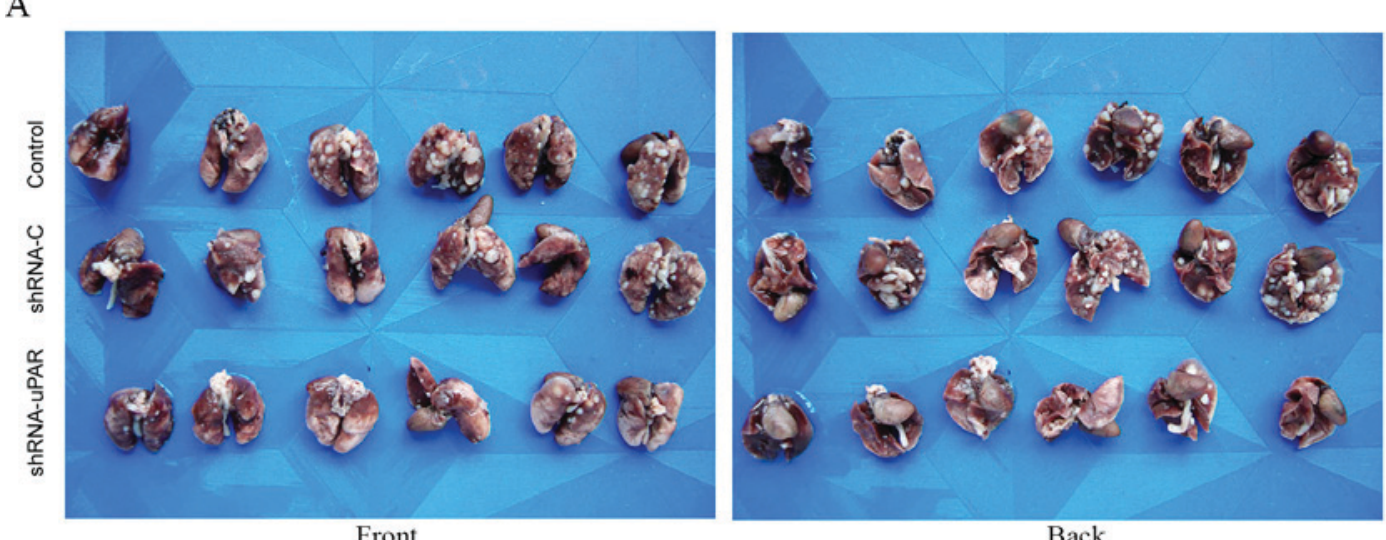

$\mathrm{B}$

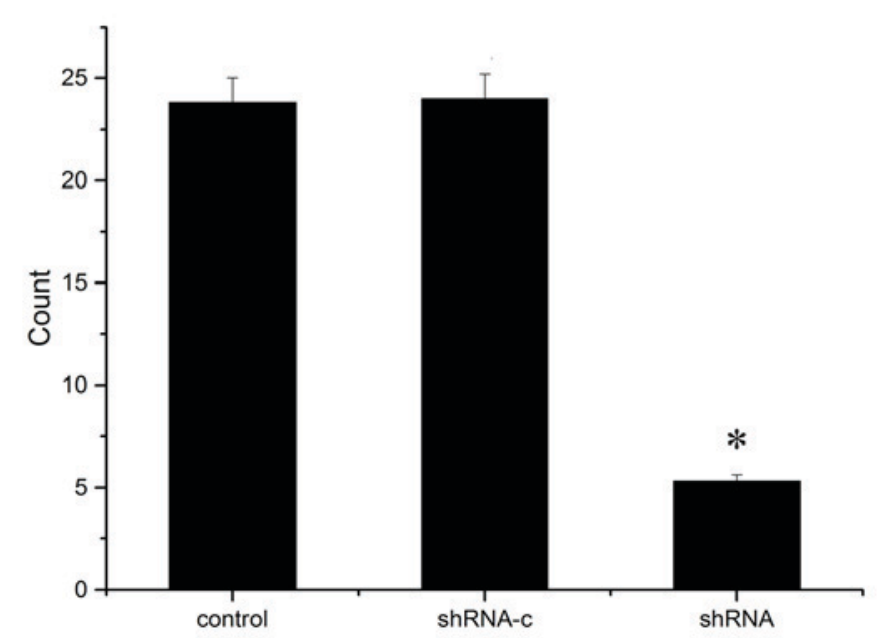

Figure 5. Silencing of uPAR suppresses the metastatic potential of Ts cells in vivo. (A) The macroscopic view of lung metastatic nodes following inoculation with Ts cells in two different perspectives. (B) The number of lung metastatic nodes. ("P<0.05, compared with the control and shRNA-C groups). uPAR, urokinase-type plasminogen activator receptor; shRNA, short hairpin RNA.

signaling pathway serves a notable role in tumorigenesis (29). ERK was determined to be overexpressed in various tumor types, including oral cancer types (30), malignant melanoma (31) and breast cancer (32). Activated Akt is required for a number of events of the metastatic pathway, including the escape of cells from the tumor environment (into and then out of the circulation), activation of proliferation, blockage of apoptosis and activation of angiogenesis (33). The results of the present study indicated that the decrease in ERK may be associated with the reduced invasion and migration, which was determined in the UPAR shRNA group, compared with the shRNA-C and control groups in vitro. Furthermore, western blot analysis of Akt activation demonstrated no significant difference in Akt phosphorylation; however, a previous study (34) indicated that downregulation of uPAR and uPA caused the dephosphorylation of p-Akt. The results of the present study indicated that there may be other methods to regulate Akt phosphorylation. A previous study (35) determined that various oncoproteins and tumor suppressors are implicated in cell signaling/metabolic regulation convergence within the Akt signal transduction pathway; however, further investigations are required. Furthermore, a significant decrease in MMP-2 and MMP-9 expression was observed in treated cells, indicating a causal role of UPAR in the invasion of Ts cells. In agreement with the results of the present study,
Randle (36) demonstrated that uPAR-induced invasion of prostate cells is mediated by MMP-2 and MMP-9; therefore, we hypothesized that uPAR signaling may be responsible for Ts cell signaling, which promotes tumor progression.

Furthermore, the results of the present in vivo experiments indicated a significant decrease in the number of metastatic nodes; however, the tumor microenvironment also contains other signals, which control tumor metastasis (37). Additionally, lung metastasis may also be involved in multiple signaling pathways such as MAPK and SMAD1 signaling pathways (38). Further research is required to confirm the present results; however, it is notable that UPAR silencing influenced tumor metastasis in vivo.

In conclusion, the present study demonstrated that the inhibition of uPAR signaling modulates the invasion and metastasis of Ts cells. Future studies to detect UPAR signaling in various stages of tumor progression and metastasis may result in the further development of a number of tumor-targeted therapies; therefore, targeted silencing of uPAR-induced signaling would provide novel treatment approaches for the management of OTSCC.

\section{Acknowledgements}

Not applicable. 


\section{Funding}

The authors received a grant from the National Natural Science Foundation of China (grant nos. 81372893 and 81773942), the International Scientific and Technological Cooperation Project of Gansu Province (grant no. 17YF1WA165) and Lanzhou University Research Funds of Stomatology (grant no. 201501-1).

\section{Availability of data and materials}

The datasets used and/or analyzed during the current study are available from the corresponding author on reasonable request.

\section{Authors' contributions}

XG and SW wrote the manuscript and made contributions to cell culture. QG and CG performed and analyzed the wound-healing and tumor cell invasion assays. JC assisted with immunohistochemistry. LZ and YZ contributed to western blot analysis. JW conducted the in vivo metastasis assay. All authors read and approved the final manuscript.

\section{Ethics approval and consent to participate}

All applicable international, national and/or institutional guidelines for the care and use of animals were followed. All procedures in studies involving human participants were performed in accordance with the ethical standards of the institutional and/or national research committee and with the 1964 Declaration of Helsinki and its later amendments or comparable ethical standards. The School of Stomatology ethics committee of Lanzhou University (Lanzhou, China) approved the patient and animal studies. Written informed consent was obtained from all individual participants included in the study.

\section{Patient consent for publication}

Patients provided consent for the publication of the present study.

\section{Competing interests}

The authors declare that they have no competing interests.

\section{References}

1. Warnakulasuriya S: Global epidemiology of oral and oropharyngeal cancer. Oral Oncol 45: 309-316, 2009.

2. Sano D and Myers JN: Metastasis of squamous cell carcinoma of the oral tongue. Cancer Metast Rev 26: 645-662, 2007.

3. Guerrero-Preston R, Soudry E, Acero J, Orera M, Moreno-López L, Macía-Colón G, Jaffe A, Berdasco M, Ili-Gangas C, Brebi-Mieville P, et al: NID2 and HOXA9 promoter hypermethylation as biomarkers for prevention and early detection in oral cavity squamous cell carcinoma tissues and saliva. Cancer Prev Res (Phila) 4: 1061-1072, 2011.

4. Rasch MG, Lund IK, Almasi CE and Hoyer-Hansen G: Intact and cleaved uPAR forms: Diagnostic and prognostic value in cancer. Front Biosci 13: 6752-6762, 2008.

5. Lee EJ, Whang JH, Jeon NK and Kim J: The epidermal growth factor receptor tyrosine kinase inhibitor ZD1839 (Iressa) suppresses proliferation and invasion of human oral squamous carcinoma cells via p53 independent and MMP, uPAR dependent mechanism. Ann N Y Acad Sci 1095: 113-128, 2007.
6. Jing Y, Bejarano MT, Kovacs K and Merchan J: Abstract 3545: Stromal selective targeting by uPAR retargeted oncolytic measles virus inhibits breast cancer progression. Cancer Res 75 (15 Suppl): Abstract nr 3545, 2015.

7. Gao N, Bozeman E, Qian W, Staley C, Wang A, Mao H and Yang L: Abstract 4593: Targeted therapy of pancreatic cancer by intraperitoneal delivery of uPAR-targeted theranostic nanoparticles. Cancer Res 74 (19 Suppl): Abstract nr 4593, 2014

8. Gorantla B, Asuthkar S, Rao JS, Patel J and Gondi CS: Suppression of the uPAR-uPA system retards angiogenesis, invasion, and in vivo tumor development in pancreatic cancer cells. Mol Cancer Res 9: 377-389, 2011.

9. Dass K, Ahmad A, Azmi AS, Sarkar SH and Sarkar FH: Evolving role of $\mathrm{uPA} / \mathrm{uPAR}$ system in human cancers. Cancer Treat Rev 34: 122-136, 2008.

10. Zh XY, Wu JZ, Liu B, et al: Establishment and characterization of a metastatic cell line from spinal cord metastasis induced by injection of tongue cancer $\mathrm{Tb}$ cells in nude mouse. J Chin Stomatol 18: 412-415, 2002 (In Chinese).

11. Wang J, Chen J, Ma M, et al: Construction and identification of specific shRNA interference plasmid vector targeted to uPAR gene. Chin Oncol 19: 904-909, 2009 (In Chinese).

12. Wu YM, Zhang XN, Han ZY, Li CY and Chen NC: Construction of shRNA expression vector pWH1 and its function in silencing the HIF1 gene. Xi Bao Yu Fen Zi Mian Yi Xue Za Zhi 24: 115-118, 2008 (In Chinese).

13. Lærum OD, Ovrebo K, Skarstein A, Christensen IJ, Alpízar-Alpízar W, Helgeland L, Danø K, Nielsen BS and Illemann M: Prognosis in adenocarcinomas of lower oesophagus, gastro-oesophageal junction and cardia evaluated by uPAR-immunohistochemistry. Int J Cancer 131: 558-569, 2012.

14. Boonstra MC, Verspaget HW, Ganesh S, Kubben FJ, Vahrmeijer AL, van de Velde CJ, Kuppen PJ, Quax PH and Sier CF: Clinical applications of the urokinase receptor (UPAR) for cancer patients. Curr Pharm Des 17: 1890-1910, 2011.

15. Mahmood T and Yang PC: Western blot: Technique, theory, and trouble shooting. N Am J Med Sci 4: 429-434, 2012.

16. Brown GT and Murray GI: Current mechanistic insights into the roles of matrix metalloproteinases in tumour invasion and metastasis. J Pathol 237: 273-281, 2015.

17. Pavón MA, Arroyo-Solera I, Céspedes MV, Casanova I, León X and Mangues R: uPA/uPAR and SERPINE1 in head and neck cancer: Role in tumor resistance, metastasis, prognosis and therapy. Oncotarget 7: 57351-57366, 2016.

18. Noh H, Hong S and Huang S: Role of urokinase receptor in tumor progression and development. Theranostics 3: 487-495, 2013.

19. Almholt K, Lærum OD, Nielsen BS, Lund IK, Lund LR, Rømer J and Jögi A: Spontaneous lung and lymph node metastasis in transgenic breast cancer is independent of the urokinase receptor uPAR. Clin Exp Metastasis 32: 543-554, 2015.

20. Margheri F, Luciani C, Taddei ML, Giannoni E, Laurenzana A, Biagioni A, Chillà A, Chiarugi P, Fibbi G and Del Rosso M: The receptor for urokinase-plasminogen activator (uPAR) controls plasticity of cancer cell movement in mesenchymal and amoeboid migration style. Oncotarget 5: 1538-1553, 2014.

21. Hu J, Muller KA, Furnari FB, Cavenee WK, VandenBerg SR and Gonias SL: Neutralizing the EGF receptor in glioblastoma cells stimulates cell migration by activating uPAR-initiated cell signaling. Oncogene 34: 4078-4088, 2015.

22. Randle DD, Clarke S, Henderson V and Odero-Marah VA: Snail mediates invasion through UPA/uPAR and the MAPK signaling pathway in prostate cancer cells. Oncol Lett 6: 1767-1773, 2013.

23. Kotipatruni RR, Nalla AK, Asuthkar S, Gondi CS, Dinh DH and Rao JS: Apoptosis induced by knockdown of uPAR and MMP-9 is mediated by inactivation of EGFR/STAT3 signaling in medulloblastoma. PLoS One 7: e44798, 2012.

24. Tang $L$ and Han $X$ : The urokinase plasminogen activator system in breast cancer invasion and metastasis. Biomed Pharmacother 67: 179-182, 2013.

25. Jiang WG, Sanders AJ, Katoh M, Ungefroren H, Gieseler F, Prince M, Thompson SK, Zollo M, Spano D, Dhawan P, et al: Tissue invasion and metastasis: Molecular, biological and clinical perspectives. Semin Cancer Biol 35 (Suppl): S244-S275, 2015.

26. Illemann M, Laerum OD, Hasselby JP, Thurison T, Høyer-Hansen G and Nielsen HJ; Danish Study Group on Early Detection of Colorectal Cancer, Christensen IJ: Urokinase-type plasminogen activator receptor (UPAR) on tumor-associated macrophages is a marker of poor prognosis in colorectal cancer. Cancer Med 3: 855-864, 2014. 
27. Marampon F, Gravina GL, Di Rocco A, Bonfili P, Di Staso M, Fardella C, Polidoro L, Ciccarelli C, Festuccia C, Popov VM, et al: MEK/ERK inhibitor U0126 increases the radiosensitivity of rhabdomyosarcoma cells in vitro and in vivo by downregulating growth and DNA repair signals. Mol Cancer Ther 10: 159-168, 2011.

28. Fresno Vara JA, Casado E, de Castro J, Cejas P, Belda-Iniesta C and González-Barón M: PI3K/Akt signalling pathway and cancer. Cancer Treat Rev 30: 193-204, 2004.

29. Yang JY, Zong CS, Xia W, Yamaguchi H, Ding Q, Xie X, Lang JY, Lai CC, Chang CJ, Huang WC, et al: ERK promotes tumorigenesis by inhibiting FOXO3a via MDM2-mediated degradation. Nat Cell Biol 10: 138-148, 2008

30. Hayashido Y, Kitano H, Sakaue T, Fujii T, Suematsu M, Sakurai S and Okamoto T: Overexpression of integrin $\alpha \mathrm{v}$ facilitates proliferation and invasion of oral squamous cell carcinoma cells via MEK/ERK signaling pathway that is activated by interaction of integrin $\alpha v \beta 8$ with type I collagen. Int J Oncol 45: 1875-1882, 2014.

31. Yajima I, Kumasaka MY, Thang ND, Goto Y, Takeda K, Yamanoshita O, Iida M, Ohgami N, Tamura H, Kawamoto Y and Kato M: RAS/RAF/MEK/ERK and PI3K/PTEN/AKT signaling in malignant melanoma progression and therapy. Dermatol Res Pract 2012: 354191, 2012.
32. Ebi H, Costa C, Faber AC, Nishtala M, Kotani H, Juric D, Della Pelle P, Song Y, Yano S, Mino-Kenudson M, et al: PI3K regulates MEK/ERK signaling in breast cancer via the Rac-GEF, P-Rex1. Proc Natl Acad Sci USA 110: 21124-21129, 2013.

33. Hong SW, Jung KH, Lee HS, Choi MJ, Son MK, Zheng HM and Hong SS: SB365 inhibits angiogenesis and induces apoptosis of hepatocellular carcinoma through modulation of PI3K/Akt/mTOR signaling pathway. Cancer Sci 103: 1929-1937, 2012.

34. Gondi CS, Kandhukuri N, Dinh DH, Gujrati M and Rao JS: Down-regulation of uPAR and UPA activates caspase-mediated apoptosis and inhibits the PI3K/AKT pathway. Int J Oncol 31: 19-27, 2007.

35. Altomare DA and Testa JR: Perturbations of the AKT signaling pathway in human cancer. Oncogene 24: 7455-7464, 2005.

36. Randle DD, Clarke S, Odero-Marah V: Abstract 2407: Snail 1 regulates invasion through uPA-uPAR and MMP-9 signaling in prostate cancer cells. Cancer Res 72 (8 Suppl): Abstract nr 2407, 2012.

37. De Craene B and Berx G: Regulatory networks defining EMT during cancer initiation and progression. Nat Rev Cancer 13: 97-110, 2013

38. Oskarsson T, Batlle E and Massagué J: Metastatic stem cells: Sources, niches, and vital pathways. Cell Stem Cell 14: 306-321, 2014. 